Pbar Note \#505

Power Handling Upgrade of Debuncher Stochastic Cooling Kicker Tanks

D. McGinnis

June, 1991 


\section{POWER HANDLING UPGRADE OF DEBUNCHER STOCHASTIC COOLING KICKER TANKS}

The Debuncher Stochastic Cooling Power Upgrade tripled the number of TWTs from 16 to 48 . The power desired for each TWT is about $120 \mathrm{~W}$. The debuncher stochastic cooling system contains 6 kicker tariks (4 short tanks, 2 long tanks) with a total number of 64 microwave feedthroughs. Thus, the power per feedthrough increased from $30 \mathrm{~W}$ to $90 \mathrm{~W}$ as a result of the upgrade.

The kicker array inside the vacuum tank is connected to the microwave feedthrough on the vacuum flange by means of a rigid 0.25 " diameter coaxial cable which is $12^{\prime \prime}$ long. With $90 \mathrm{~W}$ flowing through the coax, the amount of power dissipated is $2.5 \mathrm{~W}$. A lab test on a single debuncher kicker tank showed that this power dissipation caused the temperature of the coaxial cable to rise to greater than $175^{\circ} \mathrm{C}$. At this point the Teflon dielectric of the coax and the solder joints in the coax might seriously degrade.

As a temporary stop-gap solution, transistor heat sinks were placed around the outside of the coaxial cable. (The amount of heat sinks need for all the cables was 3400.) The primary function of the transistor heat sinks around the coaxial cable was to remove thermal energy generated in the coax by radiation. Lab tests showed that the with the heat sinks in place, the temperature of the coax was brought below $110^{\circ} \mathrm{C}$.

However, with the tanks installed, the maximum total amount of power that could be applied to the tanks and keep the ion pumps safely below their trip level (The trip level on the ion pumps is about $1 \times 10-6$ Torr. We kept the ion pumps at about $3 \times 10-7$ Torr.) was about $2250 \mathrm{~W}$ or $35 \mathrm{~W}$ per feedthrough. The ion pumps with the highest pressure in the kicker sector (D30) were D:IP202 and D:IP305. These pumps are mounted directly on the two long kicker tanks. These two long kicker tanks account for one half of the total microwave feedthroughs.

Further bench studies showed that $2.5 \mathrm{~W}$ were also dissipated in the microwave vacuum feedthrough. This $2.5 \mathrm{~W}$ that was generated caused a large temperature rise in the vacuum feedthrough because of the poor heat sinking of the feedthrough. The poor heat sinking was the result of the stainless steel walled bellowed flange on which the feedthrough is mounted.

To alleviate the vacuum problem, the two long kicker tanks were removed during the fall shutdown of 1990. The 32 bellowed flanges were replaced with solid flanges that mounted directly on the tank. The microwave feedthrough was welded into the flange and was heat 
sunk by means of a copper collar that screwed directly on to the feedthrough. The copper collar was cooled by chilled water. (See drawings 8000-MB-254652, 8000-MC-254561, 8000-MB-254562, 8000-MB-254566.)

Because there are no bellows on the new flange design, the rigid $0.25^{\prime \prime}$ diam. coaxial cable was replaced by flexible, braided $0.141^{n}$ diam. cable in order to allow a good vacuum seal. The flexible coaxial cable was heat sunk along most of its length by means of a $8^{\prime \prime}$ long copper collar. The collar itself was heat sunk to a $1^{n}$ diameter copper bar that extended to outside the vacuum tank and was water cooled. (See drawings 8000-MB-254563 and 8000-MC254564) The water cooling of the copper bar for each feedthrough was tied in series by $3 / 8^{n}$ copper water line. The $3 / 8^{n}$ copper water line itself was in series with the chilled water of the kicker tank. In this way, no flow was diverted from the chilled water into the kicker tank. The entire coax and flange assembly is shown in Fig. 1.

As an added precaution, the elbow launcher on the array was water cooled by tapping off the kicker resistor chilled water cooling lines in side the vacuum tank. The extra lines were placed in series with the existing kicker resistor water lines so as not divert any flow from the kicker resistors. The water cooled lines were attached to the launcher elbow by means of a copper clip. (See drawings $8000-\mathrm{MC}-254654$ and $8000-\mathrm{MC}-254565$ )

With the above modifications in place, the temperature of each feedthrough coax could be kept under $60^{\circ} \mathrm{C}$ with an applied power of $90 \mathrm{~W}$. Because of time constraints, the 4 short kicker tanks were not modified. Instead, the ratio of the power feeding the long tanks to the power feeding the short tanks was changed to 2:1. The power that could now be achieved while still keeping the ion pump pressure below $3 \times 10-7$ Torr was now $3600 \mathrm{~W}$ which is $2 / 3$ of the desired maximum power. This $3600 \mathrm{~W}$ corresponds to $75 \mathrm{~W}$ per feedthrough for the long tanks and $37.5 \mathrm{~W}$ per feedthrough for the short tanks.

With the power to the short tanks off, a total power of $2700 \mathrm{~W}$ could be delivered to the 2 long tanks which corresponds to $84 \mathrm{~W}$ per feedthrough. Although it is difficult to separate the outgassing rates for the different tanks, it is believed that the limitation on the vacuum is now constrained by the shorter tanks. Thus, the above cooling scheme will be applied to the 4 short tanks after the fixed target run of 1991 . 
